\title{
UTILIZATION PATTERNS OF DISEASE-MODIFYING ANTIRHEUMATIC DRUGS (DMARDS) IN PATIENTS WITH AUTOIMMUNE RHEUMATIC DISEASES
}

\author{
LAURA-ALEXANDRA ANGHEL ${ }^{1}$, DANIEL-CORNELIU LEUCUTA ${ }^{2 *}$, ANDREEA MARIA \\ FARCAS $^{3}$, RADU NICOLAE OPREAN ${ }^{1}$ \\ ${ }^{I}$ Analytical Chemistry and Instrumental Analysis, Faculty Pharmacy, University of Medicine and Pharmacy "Iuliu of \\ Hatieganu”, $4^{\text {th }}$ Pasteur Street, Cluj-Napoca, Romania. \\ ${ }^{2}$ Medical Informatics and Biostatistics, Faculty of Medicine, University of Medicine and Pharmacy "Iuliu Hatieganu", $6^{\text {th }}$ \\ Louis Pasteur Street, Cluj-Napoca, Romania. \\ ${ }^{3}$ Drug Information Research Centre, Faculty of Pharmacy, University of Medicine and Pharmacy "Iuliu Hatieganu”, $6^{\text {th }}$ \\ Louis Pasteur Street, Cluj-Napoca, Romania
}

*corresponding author: dleucuta@umfcluj.ro

Manuscript received: July 2018

\begin{abstract}
We conducted a retrospective observational study with the purpose to evaluate disease-modifying antirheumatic drugs (DMARDs) prescription trends and patterns in real-life setting and determine DMARDs prescriptions costs in Romania. We used a pharmacy claim database (all prescriptions 2011-2014), and looked at four diseases: rheumatoid arthritis (RA), ankylosing spondylitis (AS), systemic lupus erythematosus (SLE) and psoriatic arthritis (PsA) and seven drugs. Out of a total number of prescriptions (486 700), 5375 (1.1\%) were for DMARDs in 1085 patients. Leflunomide was most often prescribed (30.14\%), followed by methotrexate (24.84\%), sulfasalazine (18.67\%) and hydroxychloroquine (16.10\%). $77.2 \%$ of all prescriptions were for monotherapy. 95\% of DMARDs prescriptions costs were for RA and PsA prescriptions. Results showed an increase in DMARDs prescribing trend, with particular variations that was mainly influenced by the temporary absence of methotrexate from the Romanian market. DMARDs prescriptions costs had a steady increase during the study period.
\end{abstract}

\section{Rezumat}

Studiul de faţă este unul retrospectiv observațional în care ne-am propus evaluarea tendințelor și modificărilor de prescriere ale medicamente modificatoare ale bolii (DMARD - disease modifying antirheumatic drugs) și determinarea costurilor prescripţiilor DMARD în România. Am examinat baza de date a mai multor farmacii comunitare (toate prescripțiile din perioada 2011 - 2014) şi am urmărit patru afecţiuni: poliartrita reumatoidă, spondilita anchilozantă, lupusul eritematos sistemic şi artrita psoriazică şi şapte medicamente. Din numărul total de prescripții $(486700), 5375(1,1 \%)$ au conţinut DMARD, prescrise la 1085 pacienți. Leflunomida a fost cel mai prescris agent (30,14\%), urmată de metotrexat $(24,84 \%)$, sulfasalazină $(18,67 \%)$ și hidroxiclorochină (16,10\%). 77.2\% din prescripții au conţinut un singur DMARD. 95\% din costurile prescripțiilor a fost reprezentat de costuri pentru poliartrita reumatoidă şi spondilita anchilozantă. S-a observat o creștere a nivelului de prescriere a DMARD, cu variații individuale care au fost influențate în principal de absența temporară a metotrexatului de pe piața românească. Costurile prescripțiilor DMARD au avut o creștere constantă în timpul perioadei de studiu.

Keywords: rheumatic diseases, utilization patterns, DMARDs, pharmacy database

\section{Introduction}

Autoimmune rheumatic diseases are a group of heterogeneous chronic diseases characterized by inflammation and several other systemic manifestations. The pathophysiology involves chronic inflammation mediated by proinflammatory cytokines and dysfunctions in the signalling pathways, which ultimately affect different constituents of the immune system, resulting in varying clinical features. Patients usually experience pain, swelling, and joint tenderness, which reduces functioning in daily activities and decreases quality of life. Autoimmune rheumatic diseases can also be associated with a broad range of co-morbidities, including cardiovascular disease, malignancies, non-alcoholic fatty liver disease, infections, obesity [3-5, 22-24].

Their pathogenesis is not yet fully understood. Genetic, environmental, and immunologic factors are suspected to be instrumental in disease development. Rheumatoid arthritis (RA), ankylosing spondylitis (AS), systemic lupus erythematosus (SLE) and psoriatic arthritis (PsA) represent several important (prevalence and outcome wise) autoimmune rheumatic diseases that share similar immunemediated inflammatory pathways. Nevertheless they have some pathogenesis differences, and also distinct clinical features [5]. In the last years, an 
increased understanding of the immunopathogenesis of these diseases has supported the development of targeted treatments, but there is still more to do.

Differences in the pathogenesis of these diseases can dictate various therapeutical approaches. There are international guidelines and recommendations that support general therapeutical approaches, but they also underline the importance of individualized therapy. These arguments lead to distinctive utilization patterns [1, 3, 4, 20, 22-24].

Controlled clinical trials have determined diseasemodifying antirheumatic drugs' (DMARDs) efficacy in controlling different disease manifestations, as well as a positive risk-benefit profile .The full extent of their use can only be characterized with data from real-life settings, like the information gathered from utilization studies. Drug utilization studies in autoimmune rheumatic diseases should be a central focus point for evaluating therapy. Alongside with other sources of information, they can help to understand the current practice and to make the necessary adjustments to obtain a better management of these diseases.

A significant increase of DMARDs use, and especially of methotrexate (MTX) has been observed in several drug utilization studies from all across Europe, North America and Japan [7, 8, 15, 17, 25]. In Romania, information regarding DMARDs utilization is scarce $[2,6,21]$. The main research focus has been the use of biologic agents, which is just a part of the pharmacological treatment and disease management in autoimmune rheumatic diseases. In order to thoroughly characterize drug utilization, information about DMARDs needs to be also included, since DMARDs are the fundamental treatment for a great number of patients $[1,3,4,20$, 22-24]. The seriousness of biologic agents' potential adverse reactions, the associated high costs and the relatively short duration of observation in clinical practice limit their use. DMARDs are the first treatment option, capable of modifying the course and outcome of these diseases and improving quality of life. Therefore we consider that accurate information regarding the specific variations of DMARDs trends and patterns in real life setting is relevant for healthcare professionals, authorities and patients. Successful research in drug utilization calls for the collaboration between clinicians, epidemiologists, clinical pharmacologists and pharmacists [27].

The medical perspective is just one facet of drug utilization studies; the other is the economic aspect. According to the World Health Organization (WHO) patterns of drug use refer to the profiles, as well as the trends in drug use and costs over time. Drug costs account for a substantial part of the overall costs of healthcare, typically $10-15 \%$ in developed countries and up to $60 \%$ in low and middle-income countries [9, 27]. Concerns about medical costs in general, and pharmaceutical in particular, are expressed by all healthcare systems with a focal point on implementing quality healthcare within limited financial resources.

In the present study, we looked at four most common rheumatic diseases for a comprehensive characterization of DMARDs pattern use, since the role each agent plays in the treatment plan has unique features that give relevant information about the management of each disease.

The main objective was to provide information on DMARDs prescription patterns and to describe local trends of DMARDs therapy of autoimmune rheumatic diseases in Romania. The secondary objective was to offer an estimate of DMARDs prescriptions costs in Romania.

\section{Materials and Methods}

This was an observational retrospective study using drug dispensing records of a local network of pharmacies database. The analysed database included all prescription of reimbursed drugs dispensed between $1^{\text {th }}$ of January 2011 and $31^{\text {th }}$ of December 2014, in 9 urban pharmacies. Patients with a diagnosis of rheumatoid arthritis (RA), ankylosing spondylitis (AS), systemic lupus erythematosus (SLE) and psoriatic arthritis (PSA) were included in the present analysis. The therapy of these conditions is fully covered by the Romanian National Insurance Health System. Our cohort included patients with at least one prescription dispensed with one of the following drugs: azathioprine (AZA), cyclosporine (CYC), hydroxychloroquine (HCQ), leflunomide (LEF), methotrexate (MTX), methylprednisolone (MET) and sulfasalazine (SSZ).

De-indentified dispensation records included an anonymised patient identifier (which did not allow retrieving patient's information on age and gender), dispensing pharmacy, insurance type, drug and brand name, dosage form and the number of days covered by the prescription. Based on the drug form, brand name and the number of days covered by the prescription, a daily (for AZA, CYC, HCQ, LEF, MET, SSZ) or a weekly dose (for MTX) was calculated. Monotherapy was defined as having prescribed one DMARD per prescription and disease. Combined therapy was defined as having prescribed two or more than two different DMARDs for the same disease and on the same prescription. The most frequent associations were then determined. Estimations of prescriptions costs (for the complete time frame 2011-2014 and grouped into 2 periods 2011-2012 and 2013-2014) were also included for diseases and individuals drugs. 
Informed consent from individual patients was not needed, since this was a retrospective database study on de-identified prescription data.

\section{Statistical analysis}

Prescription data was extracted from collated databases from monthly pharmacies' prescription data exports. A script in $\mathrm{R}$ software environment for computing and graphics ( $\mathrm{R}$ Foundation for Statistical Computing, Vienna, Austria), version 3.4.3 was developed to extract only DMARD drugs, to join them in their prescriptions, to identify combined therapy, and to calculate costs. Finally the information was combined at patient level.

Qualitative data was presented using counts, percentages and line charts.

\section{Results and Discussion}

A total number of $1,456,247$ drugs in 486,700 prescriptions were analysed for the time frame. 5,375 prescriptions $(1.10 \%)$ contained the seven drugs dispensed for the four rheumatic diseases. By using the patient unique and anonymous identifier we have found that 1,085 patients received these prescriptions more than once over the study time frame.
An overall variable prescription trend could be observed over the entire period for several agents (LEF, SSZ, HCQ), beginning with an increase followed by a decrease for SSZ, as opposed to MTX (this was probably due to the MTX shortage on the market, and the compensatory increase of SSZ). The other drugs presented low variations in prescription trends (AZA, CYC) or suffered from an overall decrease (MET) (this concords to the common tendency to reduce MET usage) (Table I, Figure 1). DMARDs prescription trends

A significant fluctuation of MTX prescription trends was observed over the entire period, a decrease from $31.12 \%$ (2011) to $14.92 \%$ (2012), followed by an increase to $21.04 \%$ (2013) and reaching $30.79 \%$ (in 2014). Concomitant with MTX decreased prescriptions, an increase in LEF (from $26.24 \%$ to $34.02 \%$ ), SSZ (from $14.80 \%$ to $24.61 \%)$ and HCQ $(13.92 \%$ to $16.69 \%)$ prescriptions for the 2011 - 2012 period was observed (Table I, Figure 1). MTX was not present on the market in that period of time, and this increased the usage of other DMARDs to overcome the shortage of MTX.

Table I

Disease-modifying antirheumatic drugs (DMARDs) prescription trends 2011-2014

\begin{tabular}{cccccccc}
\hline & \multicolumn{7}{c}{ Number of dispensed DMARDs } \\
\hline Period & 2011 & 2012 & 2013 & 2014 & $2011-2012$ & $2013-2014$ & $\mathbf{2 0 1 1 - 2 0 1 4}$ \\
& & & & & & & \\
DMARDs & 1128 & 1414 & 1730 & 2267 & 2542 & 3997 & $\mathbf{6 5 3 9}$ \\
& $(100 \%)$ & $(100 \%)$ & $(100 \%)$ & $(100 \%)$ & $(100 \%)$ & $(100 \%)$ & $\mathbf{1 0 0 \%}$ \\
AZA & 59 & 45 & 81 & 112 & 104 & 193 & $\mathbf{2 9 7}$ \\
& $(5.23 \%)$ & $(3.18 \%)$ & $(4.68 \%)$ & $(4.94 \%)$ & $(4.09 \%)$ & $(4.83 \%)$ & $\mathbf{( 4 . 5 7 \% )}$ \\
SSZ & 167 & 348 & 339 & 367 & 515 & 706 & $\mathbf{1 2 2 1}$ \\
& $(14.80 \%)$ & $(24.61 \%)$ & $(19.60 \%)$ & $(16.19 \%)$ & $(29.26 \%)$ & $(17.66 \%)$ & $(\mathbf{1 8 . 6 7 \% )}$ \\
HCQ & 157 & 236 & 307 & 353 & 393 & 660 & $\mathbf{1 0 5 3}$ \\
& $(13.92 \%)$ & $(16.69 \%)$ & $(17.75 \%)$ & $(15.57 \%)$ & $(15.46 \%)$ & $(16.51 \%)$ & $(\mathbf{1 6 . 1 0 \% )}$ \\
LEF & 296 & 481 & 551 & 643 & 777 & 1194 & $\mathbf{1 9 7 1}$ \\
& $(26.24 \%)$ & $(34.02 \%)$ & $(31.85 \%)$ & $(28.36 \%)$ & $(30.75 \%)$ & $(29.87 \%)$ & $(\mathbf{3 0 . 1 4 \% )}$ \\
MTX & 351 & 211 & 364 & 698 & 562 & 1062 & $\mathbf{1 6 2 4}$ \\
& $(31.12 \%)$ & $(14.92 \%)$ & $(21.04 \%)$ & $(30.79 \%)$ & $(22.11 \%)$ & $(26.57 \%)$ & $(\mathbf{2 4 . 8 4 \% )}$ \\
MET & 76 & 62 & 58 & 52 & 138 & 110 & $\mathbf{2 4 8}$ \\
& $(6.74 \%)$ & $(4.38 \%)$ & $(3.35 \%)$ & $(2.29 \%)$ & $(5.43 \%)$ & $(2.75 \%)$ & $(\mathbf{3 . 7 9 \% )}$ \\
CYC & 22 & 31 & 30 & 42 & 53 & 72 & $\mathbf{1 2 5}$ \\
& $(1.95 \%)$ & $(2.19 \%)$ & $(1.73 \%)$ & $(1.85 \%)$ & $(2.08 \%)$ & $(1.80 \%)$ & $(\mathbf{1 . 9 1 \% )}$ \\
\hline
\end{tabular}

azathioprine (AZA), cyclosporine (CYC), disease modyfing antirheumatic drugs (DMARD), hydroxychloroquine (HCQ), leflunomide (LEF), methotrexate (MTX), methylprednisolone (MET) and sulfasalazine (SSZ)

The most prescribed DMARD over the entire period was LEF (1971, 30.14\%), followed by MTX (1624, $24.84 \%)$ and SSZ (1221, 18.67\%). This can be explained since RA and PsA have the highest prevalence between the four studied diseases. Furthermore in these two diseases DMARDs are commonly used. The most prescribed DMARDs in SLE were HCQ $(207,45.80 \%)$ and AZA (189, $41.81 \%$ ) (antimalarial and immunosuppressants are classical treatments in SLE); in AS was SSZ (382,
99.48\%) (this result is surprising since DMARDs are less used in AS, usually in peripheral AS, instead biologic therapy is the classical approach, along NSAIDs), and in RA and PsA were LEF (1971, 34.25\%), MTX (1624, 28.22\%), HCQ (867, $15.07 \%)$ and SSZ (841, 14.61\%) (these are common treatments, usually MTX is the most frequently used, but since the MTX shortage on the market it reached the second place). 
FARMACIA, 2019, Vol. 67, 1

A detailed overview of the individual DMARDs trends is seen in (Figure 1).

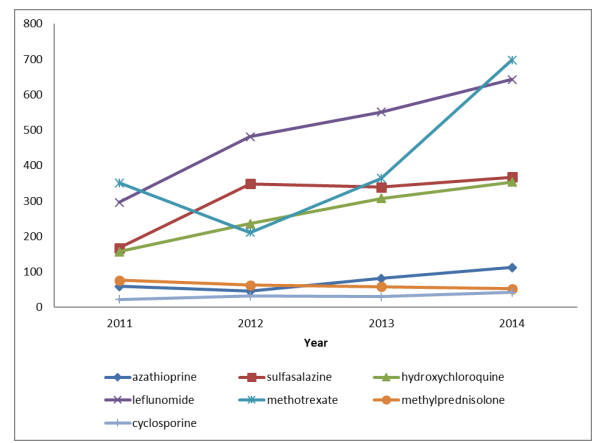

Figure 1.

Disease-modifying antirheumatic drugs (DMARDs) prescribing trends 2011-2014

DMARDs prescribing patterns

$4152(77.25 \%)$ from the total number of 5375 prescriptions contained one DMARD and 1060 $(19.72 \%)$ prescriptions had two DMARDs. The most frequent DMARDs associations were HCQLEF $(26.13 \%, 277)$ (the combination is unusual, the most common combinations are with MTX, but since it was absent on the market in a certain period, it was replaced), SSZ-LEF $(18.01 \%, 191)$ (a common combination in RA), LEF-MET (10.94\%, 116) (a common combination in RA) and HCQMTX $(10.84 \%, 115)$ (a common combination in RA). $1.66 \%$ (89) of the total prescriptions had a combination of three DMARDs prescribed for the same patient. This is a normal situation in practice. Combined therapy accounted for almost a third of the prescriptions for $\operatorname{SLE}(100,28.90 \%)$ and for almost a quarter of the prescription for RA and PsA (1070, 23.10\%); monotherapy was prevalent (99.48\%) in prescriptions for AS. All these are common in practice.

More than half $(2784,51.8 \%)$ of the DMARDs prescriptions were for elderly retired patients while almost a quarter $(1288,23.96 \%)$ for patients with a handicap (with disability pension). Just $14.42 \%$ (775) patients with DMARDs prescriptions were employed at the time of the study. These diseases occur mainly between the second and fifth decades. Many patients will be prematurely retired, due to the disease, and a proportion of them will develop a handicap. Thus these results are as expected.

The most prescribed daily doses for every agent were: $20 \mathrm{mg}$ for LEF (1782, 87.95\%), 100mg for CYC $(65,42.48 \%), 8 \mathrm{mg}$ for MET $(80,29.09 \%), 2 \mathrm{~g}$ for SSZ (599, 45.51\%), 100mg AZA (145, 45.31\%) and $400 \mathrm{mg}$ for HCQ $(869,77.17 \%)$. All these results are common in practice. For MTX the two most prescribed weekly dose were $15 \mathrm{mg}$ (510, $29.15 \%)$ and $10 \mathrm{mg}(472,26.98 \%)$. This is surprising since the recommended dose would be $20 \mathrm{mg}$ per week, but it is explained but the late availability of the $20 \mathrm{mg}$ dosage within the observed period.

DMARDs prescriptions costs

95\% represented costs for drug prescriptions for RA and PsA, which remained a constant trend over the years (Table II).

Table II

Disease-modifying antirheumatic drugs (DMARDs) prescriptions costs in RON

\begin{tabular}{cccc} 
& \multicolumn{3}{c}{ Prescription costs (RON) } \\
Disease & $\mathbf{2 0 1 1 - 2 0 1 2}$ & $\mathbf{2 0 1 3 - 2 0 1 4}$ & $\mathbf{2 0 1 1 - 2 0 1 4}$ \\
\hline SLE & $10862.5334(2.79 \%)$ & $17154.074(2.19 \%)$ & $28016.6074(2.39 \%)$ \\
RA and PsA & $369711.038(95.07 \%)$ & $749170.331(95.48 \%)$ & $1118881.37(95.35 \%)$ \\
AS & $8325.1258(2.14 \%)$ & $18274.8752(2.33 \%)$ & $26600.001(2.27 \%)$ \\
\hline Total DMARDs costs & $\mathbf{3 8 8 8 9 8 . 6 9 7}$ & $\mathbf{7 8 4 5 9 9 . 2 8}$ & $\mathbf{1 1 7 3 4 9 7 . 9 8}$
\end{tabular}

rheumatoid arthritis (RA), ankylosing spondylitis (AS), systemic lupus erythematosus (SLE) and psoriatic arthritis (PsA), disease-modifying antirheumatic drugs (DMARDs)

In 2011-2012 two thirds of DMARDs prescriptions expenses were related to LEF and only a third with MTX; while for the next period (2013-2014) the situation reversed, with MTX accounting for two thirds of the overall DMARDs costs and LEF accounting for approximately a quarter of it. For the 2011-2014 time frame almost half $(44.65 \%)$ of the total DMARDs prescriptions costs were expenses associated with MTX and around a third (35.93\%) related to LEF (Figure 2). A significant value increase of the overall DMARDs costs was observed for the entire study period (Table II). A comparison of the two time frames revealed that overall DMARDs prescriptions cost doubled. Prescriptions costs of MTX increased six times and SSZ 2.5 times while LEF prescriptions costs were 
FARMACIA, 2019, Vol. 67, 1

reduced at half of their original value (Figure 2). The increase of MTX could be explained by an increase in the usage of injectable formulation that became available in the second part of the observation time that is more expensive than the oral formulation.

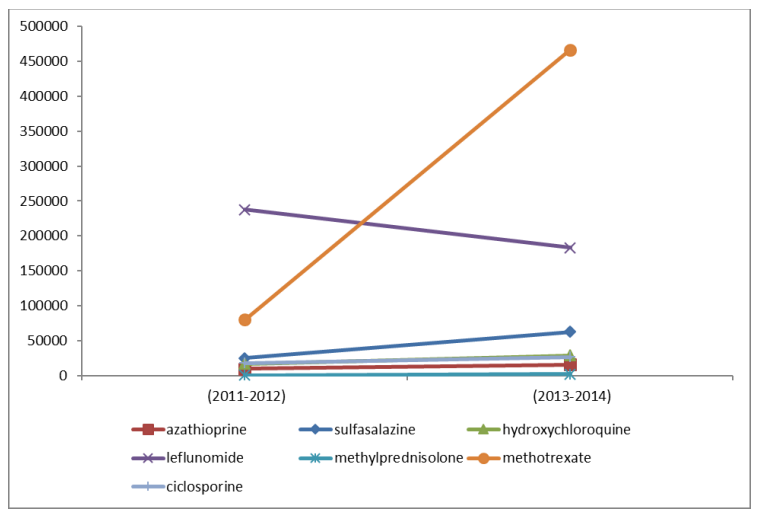

Figure 2.

Estimates of disease-modifying antirheumatic drugs (DMARDs) prescriptions costs in RON

\section{DMARDs prescription trends}

Although the general trend in our study was an increase of the overall prescribing of DMARDs, there are individual fluctuations. Among them, MTX had maybe the most impressive variation. The drastic decline noticed in 2012 could have been induced by the MTX deficiency on the Romanian market during several months. Beginning with 2013 new MTX formulations (prefilled pens for subcutaneous injection) have become available, but only in a few dosages (prefilled pens with $10 \mathrm{mg}$, but not $15 \mathrm{mg}$ and $20 \mathrm{mg}$ ), making it challenging to administer and follow individualised therapy. This problem was resolved in 2014, when MTX became available again (in oral and injectable formulations), and the proportion of prescription returned to its original value (to around a third of the total value). The majority of the MTX prescriptions were for RA and PsA, so these patients suffered the most from its absence. MTX is considered the "gold standard" for RA patients with active form of the disease and its use is preferred for some PsA patients. The concomitant increase of the dispensing of other agents (mainly SSZ and LEF) could lead to the assumption that these patients were reoriented from MTX to SSZ and LEF, and not because of clinical criteria (milder form of the disease), but as a result of MTX unavailability. Although SSZ and LEF are alternatives to MTX, there is the possibility that some of these patients did not clinically benefit from their use. The return of the overall proportion of MTX in 2014 could incline more for the explanation that these patients were reoriented to other agents just because of the lack of MTX, and then when this became available they returned to their original treatment.

Another possible explanation for the increase of the proportion of SSZ and LEF could be that in our cohort, patients did not have an active form of the disease, and did not need MTX. Sustaining this theory could be the decreasing of MET prescriptions, a glucocorticoid which is recommended to be used for only short periods of time and tapered as rapidly as possible.

LEF was the most prescribed DMARD over the entire period, which is not common in other drug utilization studies, that report MTX as being the preferred prescribed agent $[7,11,13,16,17,25]$. All of the LEF prescriptions were for RA and PsA patients. LEF has shown clinical, functional and structural efficacy, and can be considered an alternative to MTX for some RA patients. There are same safety issues that should be considered, and patients should be closely monitored [22-24]. The considerable number of LEF prescriptions found in our study could be, as explained above, a solution to the MTX absence, and not because of other clinical reasons. A study from Romania that covered RA patients over 2011-2013, reported LEF and MTX similar variation trends and provided the same explanation [2].

SSZ was also an option for patients during the period when MTX availability was not optimal. It registered an impressive increase from $14.80 \%$ in 2011 to $24.61 \%$ the year after. Different variations in the prescribing patterns of SSZ have been reported in various other studies: from being the second most prescribed agent in a cohort of RA and PsA patients [13] to a considerable decline in other cohorts [7, 17]. In our study the increase was noticeable both for RA and PsA (a possible explanation being the same need to compensate for the MTX shortage) and for AS, since SSZ is an efficient agent prescribed for AS patients. According to national and international guidelines for the treatment of AS, SSZ is the recommended agent for patients with peripheral involvement, but 
not for those with axial form of the disease. This recommendation is based on SSZ efficacy studies in AS patients with peripheral form of the disease $[4,10,12]$. Clinical data was not available in our claims database, so it is not known how many of these patients fulfilled the AS peripheral criteria. HCQ overall prescribing profile remained similar over the four years and it is in line with other findings [7, 13, 17]. HCQ was prescribed for RA, PsA and SLE. It can be used, especially in combined therapy in some RA patients that have a very mild disease form and have contraindications to other agents. It is not a first line agent for RA or PsA patients, and the fact that was the third most prescribed DMARD in our cohort, might also have been a consequence of MTX shortage. Antimalarial drugs, along with glucocorticoids and NSAIDs are the recommended treatment for SLE patients without major organ involvement [3] and findings from other studies suggest that HCQ is a highly used efficient agent for the treatment of SLE $[18,26]$. In our study it was the most dispensed agent for SLE patients.

AZA overall proportion remained constant over the period (at around 5\%) and was prescribed for SLE $(189,54.62 \%)$ and RA and PsA $(120,2.59 \%)$. This represents a small number of AZA prescriptions, but it is not surprising since it is only reserved for RA patients that have severe forms of the disease, which did not respond to other DMARDs [24]. For SLE, AZA was the second most prescribed agent after HCQ. AZA is recommended in severe, refractory SLE cases and cases of lupus nephritis or neuropsychiatric lupus as part of combination therapy $[3,18,26]$. This could suggest that half of these prescriptions could have been for patients with SLE severe cases, but not having clinical data limits the solidity of this explanation.

CYC is an immunosuppressive agent that according to international guidelines should only be used under careful monitoring for RA active forms that are refractory to several DMARDs [24]. CYC accounted for a small proportion of prescriptions $(125,1.91 \%)$ and all were for RA or PsA. Its use is restricted to rare, exceptional situations, and as a result the proportion of patients undergoing treatment is usually small and stable as seen in our cohort and other findings [2].

DMARDs prescribing patterns

DMARD monotherapy was the preferred treatment approach in our cohort, for all four diseases. There still is a lot of controversy regarding the overall superiority of the efficacy of DMARDs combined therapy vs. DMARD monotherapy, but European League against Rheumatism (EULAR) recommendation is that combined DMARDs therapy should include MTX, on the basis that other combinations have not been sufficiently studied
[24]. The utilization patterns of combined DMARDs therapy found in our study did not follow this recommendation, as the three most common DMARDs associations observed did not contained MTX. The most frequent associations (HCQ-LEF, SSZ-LEF and LEF-MET) might have been used as a substitute for MTX therapy in some patients, leading to a unique treatment pattern.

Another possible explanation for the predominant use of monotherapy could be that our cohort included patients with low disease activity that did not need combined therapy. Findings from other studies suggest that while DMARDs combined therapy is preferred in some studies [19] in others monotherapy prevails $[8,14,17,25]$. This reflects regional differences in prescribing patterns that can be influenced by circumstances such as: national regulation policies, marketing strategies of pharmaceutical companies, recommendations from national guidelines, clinical factors. Combined therapy was prevalent in a small RA cohort recruited from an outpatient clinic located in the same region as our cohort [21].

We found that combined DMARDs triple therapy was not that common in our cohort $(1.66 \%)$ and this was seen in other studies as well $[17,21]$.

Although we do not have accurate information regarding the age, our findings suggest that a half of the patients were at retirement age. RA patients tend to be older then AS or SLE patients. Generally, a diagnostic of RA is made between 50 and 60 years old, while for AS and PsA between 20 and 40, and SLE affects usually young women (1545 years old). Almost a quarter of prescriptions were for patients with a disability pension, forced into early retirement because of their disease. Our findings indicate that only a small part of the prescriptions dispensed were for employed patients (14.42\%), underlining the characteristics of our cohort.

DMARDs prescriptions costs

The significant increase of MTX prescription costs 2013-2014 compared to 2011-2012 was the result of an increase in the number of prescriptions, and also due to the introduction of new drugs formulations (prefilled pens instead of vials containing solution for intramuscular injections and tablet forms). The prefilled pens for subcutaneous injection make home administration of the weekly dose accessible to patients that before relied on weekly visits to the general practitioner office to get intramuscular injections. Patients who had contraindication or could not tolerate weekly MTX shoots could benefit beginning from 2013 from the introduction of tablet formulations, and therefore, increasing the number of MTX prescriptions. There was also a price difference between the MTX formulation that was available at the beginning of 
2011 (Methotrexat $5 \mathrm{mg} / 1 \mathrm{~mL}$ sol. inj x 10 vials $28 \mathrm{RON}$ ) and the MTX prefilled pens that were later introduced (Metotrexat $10 \mathrm{mg} / \mathrm{mL}$ x 1 syringe starting price from 59.64 RON/week - 122.5 RON/week). The total costs related to MTX therapy has been continuously increasing since 2002, when the local production stopped because of price disagreements between the producer and local authorities. Patients are not directly influenced by this increase, because the treatment for autoimmune rheumatic diseases is completely reimbursed by the National Insurance Health System. Nevertheless this has an impact on the National budget.

While there was a steady increase in LEF prescribing, the costs related to LEF decreased at half of the original value when comparing the two time periods. This was the result of the introduction of generics which offer competitive prices compared to brand-name drugs.

The present study is one of the few utilization studies performed in Romania, and is the only one that included patients from other rheumatic diseases besides RA.

Because we applied a method of data anonymization, information on gender and age could not been retrieved. Gender-specific and age-related variations reported from utilization studies in rheumatic diseases are regularly referring to common gender and age distributions patterns that are disease related.

The coding of the diagnosis made it difficult to accurately estimate individualised DMARDs utilization for RA and PsA. At a national level these two conditions share the same dispensing list, and only access to national dispensing data could lead to precise information.

The research setting limited the data to a regional size so there might have been some particularities of the included population that might not represent the entire DMARDs users in our country. Our study reflected prescribing patterns just for this region, information that would have been otherwise lost in a large, national study. For a comprehensive image of the extent and patterns of DMARDs utilization we would suggest follow-up studies using longitudinal data during the last decade from all over the country, in order to better capture national variations.

We provided data on estimates of prescriptions costs which gives a general overview of the expenses associated with DMARDs treatment. For a correct analysis this data should be interpreted in a wider context and examined together with results from cost-effectiveness studies. Up tonow there are no such studies in our country.

\section{Conclusions}

The absence of MTX on the Romanian market influenced DMARDs prescribing trends in rheumatic diseases in 2011-2014 period, setting an unique pattern of increased LEF and SSZ prescribing. Monotherapy was prevalent and LEF was the most prescribed DMARD over the entire period. DMARDs prescriptions costs had a significant increase, with almost half of the total amount accounting for MTX.

\section{References}

1. American College of Rheumatology Subcommittee on Rheumatoid Arthritis Guidelines. Guidelines for the management of rheumatoid arthritis: 2002 Update. Arthritis Rheum., 2002; 46(2): 328-346.

2. Ancuta I, Dynamics and adherence to biological therapy for rheumatoid arthritis, ankylosing spondylitis and psoriatic arthritis in Romania in 2009-2013. Rom Soc Rheumatol., 2014; 23(2): 70-86 [Title available in Romanian].

3. Bertsias G, Ioannidis JP, Boletis J, Bombardieri $\mathrm{S}$, Cervera R, Dostal C, Font J, Gilboe IM, Houssiau F, Huizinga T, Isenberg D, Kallenberg CG, Khamashta M, Piette JC, Schneider M, Smolen J, Sturfelt G, Tincani A, van Vollenhoven R, Gordon C, Boumpas DT, Task Force of the EULAR Standing Committee for International Clinical Studies Including Therapeutics, EULAR recommendations for the management of systemic lupus erythematosus. Report of a Task Force of the EULAR Standing Committee for International Clinical Studies Including Therapeutics. Ann Rheum Dis., 2008; 67(2): 195-205.

4. Braun J, van den Berg R, Baraliakos X, Boehm $\mathrm{H}$, Burgos-Vargas R, Collantes-Estevez E, Dagfinrud H, Dijkmans B, Dougados M, Emery $\mathrm{P}$, Geher $\mathrm{P}$, Hammoudeh $\mathrm{M}$, Inman RD, Jongkees M, Khan MA, Kiltz U, Kvien T, Leirisalo-Repo M, Maksymowych WP, Olivieri I, Pavelka K, Sieper J, Stanislawska-Biernat E, Wendling D, Ozgocmen S, van Drogen C, van Royen B, van der Heijde D, 2010 update of the ASAS/EULAR recommendations for the management of ankylosing spondylitis. Ann Rheum Dis., 2011; 70(6): 896-904.

5. Coates LC, FitzGerald O, Helliwell PS, Paul C, Psoriasis, psoriatic arthritis, and rheumatoid arthritis: Is all inflammation the same? Semin Arthritis Rheum., 2016; 46(3): 291-304.

6. Codreanu C, Mogosan C, Ionescu R, Ancuta I, Opris D, Biologic therapy in rheumatoid arthritis: Results from the Romanian registry of rheumatic diseases one year after initiation. Farmacia, 2014; 62(6): 1089-1096.

7. Donges E, Staatz CE, Benham H, Kubler P, Hollingworth SA, Patterns in use and costs of conventional and biologic disease-modifying anti-rheumatic drugs in Australia. Clin Exp Rheumatol., 2017; 35(6): 907-912. 
FARMACIA, 2019, Vol. 67, 1

8. Edwards CJ, Campbell J, van Staa T, Arden NK, Regional and temporal variation in the treatment of rheumatoid arthritis across the UK: a descriptive register-based cohort study. $B M J$ Open, 2012; 2(6): 1-7.

9. Elseviers $\mathrm{M}$, Wettermark $\mathrm{B}$, Almarsdóttir $\mathrm{AB}$, Andersen M, Benko R, Bennie M, Eriksson I, Godman B, Krska J, Poluzzi E, Taxis K, Vlahovic-Palcevski V, Stichele RV, Drug utilization research: Methods and applications. Chichester, UK: John Wiley \& Sons, Ltd; 2016. $536 \mathrm{p}$.

10. Fagerli KM, van der Heijde D, Heiberg MS, Wierød A, Kalstad S, Rødevand E, Mikkelsen K, Kvien TK, Lie E, Is there a role for sulphasalazine in axial spondyloarthritis in the era of TNF inhibition? Data from the NORDMARD longitudinal observational study. Rheumatology, 2014; 53(6): 1087-1094.

11. Fassmer AM, Garbe E, Schmedt N, Frequency and trends of disease-modifying antirheumatic drug (DMARD) use in Germany. Pharmacol Res Perspect., 2016; 4(5): 1-8.

12. Haibel H, Specker C, Disease-modifying antirheumatic drugs in rheumatoid arthritis and ankylosing spondylitis. Clin Exp Rheumatol., 2009; 27(4 Suppl 55): S159-S163.

13. Helliwell PS, Taylor WJ, CASPAR Study Group, Treatment of psoriatic arthritis and rheumatoid arthritis with disease modifying drugs - comparison of drugs and adverse reactions. J Rheumatol., 2008; 35(3): 472-476.

14. Jin XM, Lee J, Choi NK, Seong JM, Shin JY, Kim YJ, Kim MS, Yang BR, Park BJ, Utilization patterns of disease-modifying antirheumatic drugs in elderly rheumatoid arthritis patients. $J$ Korean Med Sci., 2014; 29(2): 210-216.

15. Katada H, Yukawa N, Urushihara H, Tanaka S, Mimori T, Kawakami K, Prescription patterns and trends in anti-rheumatic drug use based on a large-scale claims database in Japan. Clin Rheumatol., 2015; 34(5): 949-956.

16. Lie E, Fagerli KM, Mikkelsen K, Rødevand E, Lexberg Å, Kalstad S, Uhlig T, Kvien TK, Firsttime prescriptions of biological diseasemodifying antirheumatic drugs in rheumatoid arthritis, psoriatic arthritis and axial spondyloarthritis 2002-2011: data from the NOR-DMARD register. Ann Rheum Dis., 2014; 73(10): 1905-1906.

17. Ng B, Chu A, Khan MM, A retrospective cohort study: 10-year trend of disease-modifying antirheumatic drugs and biological agents use in patients with rheumatoid arthritis at Veteran Affairs Medical Centers. BMJ Open, 2013; 3(4): $1-7$.

18. Nørgaard JC, Stengaard-Pedersen K, Nørgaard $\mathrm{M}$, de Thurah A, Antimalarials in the treatment of systemic lupus erythematosus: a registrybased cohort study in Denmark. Lupus, 2015; 24(3): 299-306.

19. Rantalaiho V, Kautiainen H, Virta L, Korpela M, Möttönen T, Puolakka K, Trends in treatment strategies and the usage of different disease- modifying anti-rheumatic drugs in early rheumatoid arthritis in Finland. Results from a nationwide register in 2000-2007. Scand $J$ Rheumatol., 2011; 40(1): 16-21.

20. Salliot C, van der Heijde D, Long-term safety of methotrexate monotherapy in patients with rheumatoid arthritis: a systematic literature research. Ann Rheum Dis., 2009; 68(7): 11001104.

21. Schiotis RE, Goșa D, Bocşan C, Suciu Ş, Buzoianu AD, Particularities of treatment with conventional synthetic disease-modifying antirheumatic drugs (DMARDs) in a group of patients with rheumatoid arthritis. Farmacia, 2017; 65(3): 479-484

22. Smolen JS, Braun J, Dougados M, Emery P, Fitzgerald O, Helliwell P, Kavanaugh A, Kvien TK, Landewé R, Luger T, Mease P, Olivieri I, Reveille J, Ritchlin C, Rudwaleit M, Schoels M, Sieper J, Wit Md, Baraliakos X, Betteridge N, Burgos-Vargas R, Collantes-Estevez E, Deodhar A, Elewaut D, Gossec L, Jongkees $M$, Maccarone M, Redlich K, van den Bosch F, Wei JC, Winthrop K, van der Heijde D, Treating spondyloarthritis, including ankylosing spondylitis and psoriatic arthritis, to target: recommendations of an international task force. Ann Rheum Dis., 2014; 73(1): 6-16.

23. Smolen JS, Landewé R, Breedveld FC, Buch M, Burmester G, Dougados M, Emery P, GaujouxViala C, Gossec L, Nam J, Ramiro S, Winthrop $\mathrm{K}$, de Wit M, Aletaha D, Betteridge N, Bijlsma JW, Boers M, Buttgereit F, Combe B, Cutolo M, Damjanov N, Hazes JM, Kouloumas M, Kvien TK, Mariette X, Pavelka K, van Riel PL, Rubbert-Roth A, Scholte-Voshaar M, Scott DL, Sokka-Isler T, Wong JB, van der Heijde D, EULAR recommendations for the management of rheumatoid arthritis with synthetic and biological disease-modifying antirheumatic drugs: 2013 update. Ann Rheum Dis., 2014; 73(3): 492-509.

24. Smolen JS, Landewe R, Breedveld FC, Dougados M, Emery P, Gaujoux-Viala C, Gorter S, Knevel R, Nam J, Schoels M, Aletaha D, Buch M, Gossec L, Huizinga T, Bijlsma JW, Burmester G, Combe B, Cutolo M, Gabay C, Gomez-Reino J, Kouloumas M, Kvien TK, Martin-Mola E, McInnes I, Pavelka K, van Riel P, Scholte M, Scott DL, Sokka T, Valesini G, van Vollenhoven R, Winthrop KL, Wong J, Zink A, van der Heijde D. EULAR recommendations for the management of rheumatoid arthritis with synthetic and biological disease-modifying antirheumatic drugs. Ann Rheum Dis., 2010; 69(6): 964-975.

25. Soderlin MK, Lindroth Y, Jacobsson LTH, Trends in medication and health-related quality of life in a population-based rheumatoid arthritis register in Malmo, Sweden. Rheumatology, 2007; 46(8): 1355-1358.

26. Sugai DY, Gustafson CJ, De Luca JF, Davis SA, Jorizzo JL, O'Rourke KS, Feldman SR, Trends in the outpatient medication management of lupus 
FARMACIA, 2019, Vol. 67, 1

erythematosus in the United States. $J$ Drugs Dermatol., 2014; 13(5): 545-552.
27. World Health Organization. Introduction to Drug Utilization Research 2003 (available at http://apps.who.int.) 